\title{
Tree invasion of a montane meadow complex: temporal trends, spatial patterns, and biotic interactions
}

\author{
Charles B. Halpern, Joseph A. Antos, Janine M. Rice, Ryan D. Haugo \& Nicole L. Lang
}

\begin{abstract}
Questions: Do spatial and temporal patterns of encroachment of Pinus contorta and Abies grandis in a montane meadow suggest strong biotic controls on the invasion process?

Location: Forest-meadow mosaic, $1350 \mathrm{~m}$ a.s.1., Cascade Range, Oregon, US.

Methods: We combined spatial point pattern analysis, population age structures, and a time-series of stem maps to quantify spatial and temporal patterns of conifer invasion over a 200 -yr period in three plots totaling 4 ha.

Results: Trees established during two broad, but distinct periods (late 1800 s, then at much greater density in the mid-1900s). Recent invasion was not correlated with climatic variation. Abies grandis dominated both periods; $P$. contorta established at lower density, peaking before $A$. grandis. Spatially, older ( $\geq 90 \mathrm{yr}$ ) $P$. contorta were randomly distributed, but older $A$. grandis were strongly clumped $(0.2-20 \mathrm{~m})$. Younger $(<90 \mathrm{yr})$ stems were positively associated at small distances (both within and between species), but were spatially displaced from older $A$. grandis, suggesting a temporal shift from facilitation to competition. Establishment during the 1800 s resulted in widely scattered $P$. contorta and clumps of $A$. grandis that placed most areas of meadow close to seed sources permitting more rapid invasion during the mid-1900s. Rapid conversion to forest occurred via colonization of larger meadow openings - first by shade-intolerant $P$. contorta, then by shade-tolerant $A$. grandis - and by direct infilling of smaller openings by $A$. grandis.
\end{abstract}

Halpern, C.B. (corresponding author, chalpern@u. washington.edu), Haugo, R.D. (haugor@u.washington. edu) \& Lang, N.L. (nlang25@yahoo.com): School of Forest Resources, University of Washington, Box 352100, Seattle, WA 98195-2100 USA.

Antos, J.A. (jantos@uvic.ca): Department of Biology, PO Box 3020, STN CSC, University of Victoria, Victoria, B.C. V8W 3N5 Canada.

Rice, J.M. (ricejan@science.oregonstate.edu): Department of Geosciences, 104 Wilkinson Hall, Oregon State University, Corvallis, OR, 97331-5506 USA.
Conclusions: In combination, spatial and temporal patterns of establishment suggest an invasion process shaped by biotic interactions, with facilitation promoting expansion of trees into meadows and competition influencing subsequent forest development. Once invasion is initiated, tree species with different life histories and functional traits can interact synergistically to promote rapid conversion of meadow to forest under a broad range of climatic conditions.

Keywords: Abies grandis; Competition; Ecosystem conversion; Facilitation; Grassland invasion by trees; Mountain meadows; Pinus contorta; Tree age structure; Tree spatial structure.

Nomenclature: Hitchcock \& Cronquist (1973).

\section{Introduction}

Woody plant invasions of grasslands and meadows are of global importance (Archer et al. 1988; Van Auken 2000). Conversion of grassland to woodland or forest alters community structure and species composition (Scholes \& Archer 1997; Haugo \& Halpern 2007) and can affect nutrient cycling and carbon storage (Jackson et al. 2002; Browning et al. 2008). Numerous factors have contributed to widespread invasion of grasslands by woody plants during the past century. Although changes in climate are often implicated (e.g., Rochefort et al. 1994; Bond \& Midgley 2000; Van Auken 2000), climate is unlikely to be the sole factor given the broad range of environments in which invasions are occurring. Fire often maintains the open structure of grasslands, thus in some systems, fire suppression may be pivotal in this process (e.g., Jurena \& Archer 2003; Heyerdahl et al. 2006; Coop \& Givnish 2008). Alternatively, changes in grazing regime may facilitate invasion through disturbance or reduction in fine fuels that carry fire (Vale 1981; Scholes \& Archer 1997).

Although invasions of grasslands may be triggered by one or more exogenous factors, more proximally they may reflect changes in the strength or direction of biotic interactions that allow for successful establishment and growth of woody plants. For example, factors that reduce herbaceous 
competition can allow for germination and survival of shrubs or trees in areas where they are typically excluded (Peltzer 2001; Picon-Cochard et al. 2006). Facilitation can contribute to woody plant invasions if initial establishment and growth cause changes in physical or biological environments (e.g., microclimate, soils, or competing herbaceous species) that increase the likelihood of subsequent establishment (Hibbard et al. 2001; Dickie et al. 2005; Kennedy \& Sousa 2006). Moreover, woody species can differ in their abilities to respond to or mediate these changes (e.g., Callaway 1998; Haugo \& Halpern 2010). Thus, species with differing life histories or physiological traits can play different roles in the invasion process. Ultimately, biotic interactions, and facilitation in particular, may be fundamental in the conversion of grassland to shrubland or forest if they allow for ongoing recruitment at times when climate or other factors would otherwise inhibit establishment.

Tree invasions of grasslands or meadows often occur in ecotonal (edge) environments, either because of greater seed rain or habitat modification at the edge (Magee \& Antos 1992; Coop \& Givnish 2007). This results in gradual movement of the edge (e.g., Weltzin \& McPherson 1999; Dovčiak et al. 2008). However, trees can also establish in open areas away from edges, with initial recruits facilitating further invasion of conspecifics or other species. This pattern of nucleation (Yarranton \& Morrison 1974) can accelerate the pace at which grassland is converted to forest by initiating new foci for expansion (Archer et al. 1988; Duarte et al. 2006; Boulant et al. 2008). Both sets of processes, edge movement and nucleation, underscore the potential for biotic interactions to mediate the spatial and temporal dynamics of tree invasion.

In many ecosystems, meadow-forest boundaries represent long-standing, but dynamic tension zones, with periods of invasion punctuated by disturbances (e.g., fire) that subsequently remove trees (Hadley 1999; Norman \& Taylor 2005; Coop \& Givnish 2007). Both meadow and forest communities are likely to exhibit considerable inertia: meadow plants cannot invade forest in the absence of disturbance, and trees cannot establish in meadows unless they overcome physical barriers (e.g., dense litter) and competitive interactions with meadow plants. Identifying the factors that have contributed to past or recent changes in forestmeadow boundaries can be challenging. To date, most retrospective studies have focused almost exclusively on how the temporal patterns of invasion relate to extrinsic factors - namely, variation in climate or disturbance history (e.g., grazing or fire;
Vale 1981; Jakubos \& Romme 1993; Rochefort et al. 1994; Miller \& Halpern 1998; Hadley 1999; Norman \& Taylor 2005). In contrast, few studies of meadow invasion by trees have considered the spatial structure of establishment and the potential for biotic interactions (inferred from spatial pattern) to mediate the invasion process once it has begun. In this paper, we combine analysis of spatial and temporal patterns to reconstruct nearly two centuries of conifer invasion at Bunchgrass Ridge, a mosaic of dry montane meadows and forests in the western Cascade Range of Oregon. Here, conifer encroachment has been rapid during the past century (Haugo \& Halpern 2007), as it has in meadows throughout the Pacific Northwest (e.g., Vale 1981; Miller \& Halpern 1998; Takaoka \& Swanson 2008). Moreover, the principal invaders, Pinus contorta and Abies grandis, differ in life history and ecophysiology. $P$. contorta is intolerant of shade, establishes in open (often harsh) conditions, exhibits rapid juvenile growth, and is relatively short-lived (Minore 1979; Lotan \& Critchfield 1990). In contrast, A. grandis is shadetolerant (but can also establish in open conditions), is more sensitive to drought, has slower juvenile growth, and is longer lived (Minore 1979; Foiles et al. 1990). Thus there is the potential for these species to play different roles during invasion, including the timing of establishment and the physical and biotic context(s) in which they occur.

We address the following questions: (1) How have rates of invasion changed over the past two centuries? Can temporal trends be explained by climatic variation or do they suggest that other factors are important? (2) How is establishment spatially structured? (3) Is there evidence of biotic interactions (positive or negative) in the spatial associations of stems? (4) Have P. contorta and A. grandis contributed differently to the dynamics of invasion?

\section{Methods}

\section{Study area}

Bunchgrass Ridge forms a gently sloping $(<5 \%)$ plateau at ca. $1350 \mathrm{~m}$ a.s.l. on the western margin of the High Cascades Province in western, central Oregon $\left(44^{\circ} 17^{\prime} \mathrm{N}, 121^{\circ} 57^{\prime} \mathrm{W}\right)$. The 100 -ha study area is a mosaic of dry meadows, young ( $<90$-yr-old) forests resulting from recent invasion, and older forests reflecting past invasion. Meadow communities are comprised of graminoids (primarily Festuca idahoensis and Carex pensylvanica), and a diversity of forbs (Haugo \& Halpern 2007; Lang \& Halpern 
2007), and are comparable to other Festuca-dominated grasslands of the western Cascades (Franklin \& Halpern 1999). Grasslands of this type are common along steep, south-facing slopes and on high-elevation plateaus in this region, although their origin and maintenance are poorly understood. Evidence of forests predating current stands at Bunchgrass Ridge (e.g., old decayed logs or fire-scarred trees) is lacking. Current stands are dominated by $A$. grandis and $P$. contorta is common. Various other tree species are present, but infrequent.

The climate is characterized by cool, wet winters and warm, dry summers. At Santiam Pass (1488 m a.s.1.; $17 \mathrm{~km}$ to the north) temperatures average $-6.9^{\circ} \mathrm{C}$ (minimum) and $0.7^{\circ} \mathrm{C}$ (maximum) in January and $6.1^{\circ} \mathrm{C}$ and $27.8^{\circ} \mathrm{C}$ in July. Annual precipitation averages $216 \mathrm{~cm}$; however, only $7.5 \%$ of this falls during June through August, resulting in late-summer drought (data for 1948-1985; Western Regional Climate Center; http://www.wrcc.dri.edu/ summary/climsmor.html). Annual snowfall averages $11.5 \mathrm{~m}$, producing deep snowpacks that can persist into late spring.

Soils at Bunchgrass Ridge are deep $(>1.7 \mathrm{~m})$ fine to very fine sandy loams derived from andesitic basalt and tephra deposits with varying amounts of glacially derived rock. They grade from Vitric Melanocryands in open meadows to Aquic Vitricryands in older forests. Soil profiles indicate persistence of grasslands for centuries, even in areas currently supporting older trees (D. Lammers, pers. comm., soil scientist, US Forest Service, February 2005).

It is likely that sheep were grazed at Bunchgrass Ridge in the late 1800s and early 1900s, synchronous with widespread grazing of meadows throughout the Oregon Cascades (Burke 1979; Rakestraw \& Rakestraw 1991). Deteriorating range conditions and increasing conflicts with recreational users led to closure of all grazing allotments in this region by the mid-1900s (Elliot 1946; Johnson 1985). Specific documentation on the timing or intensity of grazing at Bunchgrass Ridge, however, is lacking in federal archives.

Forests of this region are characterized by a mixed-severity fire regime; natural fire-return intervals are $>100 \mathrm{yr}$ at this elevation (Teensma 1987; Morrison \& Swanson 1990; Weisberg \& Swanson 2003). The absence of fire scars on live trees or stumps suggests that moderate to high intensity fire has not occurred for many decades (or centuries). Native Americans or European settlers may have set low-intensity fires to keep meadows open (Burke 1979; Boyd 1999), but direct evidence or records of these activities are lacking for Bunchgrass Ridge.

\section{Field sampling and tree age determination}

Using historical aerial photographs (Haugo \& Halpern 2007) and extensive field reconnaissance, we established nine 1 -ha $(100 \mathrm{~m} \times 100 \mathrm{~m})$ plots where invasion had been evident during the past century. Each plot was selected to include areas of open meadow, recent encroachment, and older forest. These plots also served as experimental units for a larger restoration experiment (JFSP, 2009; see also http://depts.washington.edu/bgridge/). Six of the nine plots were randomly selected for tree removal, of which four were selected for intensive analysis of age structure and spatial patterning; these were distributed over an area of ca. 16 ha. Two plots shared a common edge and for this study were treated as a single 2 -ha $(200 \mathrm{~m} \times 100 \mathrm{~m})$ plot.

Within each plot we established a $10 \mathrm{~m} \times 10 \mathrm{~m}$ grid, then spatially mapped (to the nearest $0.1 \mathrm{~m}$ ) all live trees $\geq 1.4-\mathrm{m}$ tall $(n=5486)$ and all snags $\geq 5$-cm dbh $(n=1386)$. All stems were measured for diameter at breast height (dbh); decay class was also recorded for snags (Cline et al. 1980). Smaller trees (0.1-1.4-m tall) were tallied by species in four 1 $\mathrm{m} \times 1-\mathrm{m}$ quadrats aligned along a diagonal of each $10 \mathrm{~m} \times 10$-m grid cell.

All live trees $\geq 1.4-\mathrm{m}$ tall were aged from increment cores or basal sections collected in 2003 or 2004. Trees greater than ca. $10-\mathrm{cm}$ dbh $(n=1965)$ were cored as close to the ground as possible and smaller trees $(n=3521)$ were cut to obtain a basal section; height of the core or cut surface was recorded. Cores and basal sections were sanded and prepared following standard dendrochronological methods (Stokes \& Smiley 1968). Annual rings were counted under $\times 10$ to $\times 40$ magnification. For cores lacking pith, we used a series of ring-pattern templates to estimate the number of absent rings. Ring counts for trees with rotten or incomplete cores $(n=135)$ were estimated using species-specific regression equations of age vs diameter developed from the large number of trees with confirmed ages (C.B. Halpern, unpubl. data). Final ages included an adjustment for age-to-sample height based on regression equations developed from a destructive sample of 30-40 seedlings per species (C.B. Halpern, unpubl. data).

\section{Analysis}

\section{Temporal patterns of establishment and correlations} with climate

To quantify temporal patterns of tree invasion, we developed population age structures (using 5-yr 
age classes) for $P$. contorta, $A$. grandis, and all other species combined for each plot, and for all plots combined (4 ha total). Age structures do not account for trees that died and thus provide a conservative measure of establishment, i.e., the effective or net establishment of trees in these meadows.

To determine whether temporal trends could be explained by variation in climate, we calculated Pearson correlations between the number of $P$. contorta or A. grandis in each 5-yr age class and several measures of climate for the same periods. From among a larger set of climatic variables we focused on two that were previously shown to correlate strongly with conifer invasion of meadows in this region (Miller \& Halpern 1998): summer (June-August) temperature (negative correlation) and summer precipitation (positive correlation) (Division 4, Cascade Range; Anonymous 1990). We also considered a third variable, April snow depth, a proxy for length of the growing season and availability of early summer moisture (snow depth data, Three Creeks Meadow, Oregon, $1925 \mathrm{~m}$ a.s.l.; Oregon Climate Service, Portland, OR). We limited these analyses to the period of reliable weather records for the Cascades (as of 1895 for temperature and precipitation, and 1928 for snow depth). Climatic data were expressed as standard deviations from the mean ( $Z$ scores).

\section{Spatial patterns of association}

Population age structures revealed two broad, but distinct periods of establishment. These served as the basis for defining two age classes used in the analysis of spatial pattern: trees $<90 \mathrm{yr}$ old (henceforth "young") and trees $\geq 90 \mathrm{yr}$ old (henceforth "old"). Preliminary analyses with a larger number of age classes yielded similar interpretations, but resulted in smaller sample sizes and poorer ability to demonstrate statistical significance. Thus we only report results for the two age classes clearly apparent in the age structure. Only $P$. contorta and A. grandis were sufficiently abundant to analyze.

Although their establishment dates were not determined, snags contain important information on the development of spatial structure; thus, we included in the spatial analyses snags that could be unequivocally assigned to one of the two age classes. Specifically, for $P$. contorta, we added to the old class all snags $>37-\mathrm{cm}$ dbh $(n=75)$; all live $P$. contorta $>37 \mathrm{~cm}$ were older than $90 \mathrm{yr}$. For $A$. grandis, we added to the old class all snags $>60-\mathrm{cm}$ dbh $(n=33)$ using the same criterion. To the young class we added all $P$. contorta snags $<30-\mathrm{cm}$ dbh $(n=651)$. Although all live stems $<37-\mathrm{cm} \mathrm{dbh}$ were $<90$ yr old, we chose a smaller, more conservative threshold. We did not include small A. grandis snags because small trees of this shadetolerant species exhibit a wide range of ages (C.B. Halpern, unpubl. data).

Analyses were structured in four ways to explore the spatial and temporal associations of stems. First, we analyzed spatial point patterns within each age class of $P$. contorta and $A$. grandis. Second, we analyzed patterns of spatial association between $P$. contorta and $A$. grandis of the same age class. Third, we analyzed patterns of association between young and old classes of the same species, and finally, between young and old classes of different species.

We quantified spatial patterns with the Ripley K-function (Ripley 1977), a method widely used in studies of mapped individuals (e.g., Moeur 1993; Parish et al. 1999; Lingua et al. 2008). To examine patterns within each age class of $P$. contorta and A. grandis, we used the univariate form of Ripley's $K$ (Ripley 1977), correcting for edge effects to obtain $K(d)$, where $d$ are the distances tested. For ease of interpretation, we use $L(d)$, the square-root transformation of $K(d)$, which has an expected value of 0 if individuals are randomly distributed (Wiegand \& Moloney 2004). To describe patterns of association between species or age classes, we used the bivariate form of Ripley's $K$, and present the transformed value, $L_{12}(d)$, which has an expected value of 0 if the points of one group are independently distributed relative to points of the second group, up to the distance tested, $d$. For both uni- and bivariate forms of $L$, values $>0$ indicate a positive association (aggregation or attraction) and values $<0$ indicate repulsion or inhibition up to the indicated distance. Analyses were performed at $0.2-\mathrm{m}$ intervals (the lag distance) from 0.2 to $20.0 \mathrm{~m}$, although we focus on relationships at shorter distances because these are more likely to reflect interactions among neighbors (facilitation or competition). Tests were run separately for each of the three plots. Confidence bounds (simulation envelopes) were calculated using a Poisson-process model for the number of points in the sample (the bivariate method uses two Poissonprocess models) (Goreaud \& Pelissier 2003; Wiegand \& Moloney 2004). Models were simulated 100 times, and minimum and maximum values were plotted representing the lower and upper 99\% confidence bounds (see also Parish et al. 1999; Sanchez Meador et al. 2009). Analyses were conducted in S-PLUS 6 (www.tibco.com).

Although widely used, Ripley's $K$ requires care in interpretation. Because it is a cumulative function, values at larger distances can be influenced by 
values at smaller distances (e.g., Perry et al. 2006). Thus, we focus on patterns at smaller distances (i.e., $<3-5 \mathrm{~m}$, the distances over which facilitation and competition are likely to be most intense), and consider patterns at smaller distances when making interpretations at larger distances. The conventional use of simulation envelopes has been criticized for underestimating type I error, a result of many nonindependent tests at increasing distances (Loosmore $\&$ Ford 2006). We do not consider this a problem for our analysis because $L$ values greatly exceeded the narrow simulation envelopes in most instances. Moreover, we use $99 \%$ confidence bounds, focus on smaller distances, and interpret the significance of results at all distances with caution.

\section{Time-series of stem maps}

Demonstrating that trees deviate from complete spatial randomness either through aggregation or repulsion cannot fully describe the spatial or temporal dynamics of invasion (e.g., invasion along existing edges or formation of new foci away from edges). To explore the dynamics of invasion more fully, we created a time-series of stem maps for each plot displaying the locations of all stems older than the map dates. Four dates were chosen to capture key points in the invasion process: 1915 (before 20th century encroachment), 1945 (maximum rate of P. contorta establishment), 1960 (maximum rate of A. grandis establishment), and 2004 ("present"). Large snags meeting the size criteria for "old stems" ( $\geq 90 \mathrm{yr}$ ) were included in the 1915 maps (but not more recent maps) for consistency with spatial point pattern analyses.

\section{Results}

\section{Temporal patterns of establishment}

Abies grandis dominated all plots in both density ( $83 \%$ of live stems) and basal area ( $84 \%$ of live basal area; Table 1). Pinus contorta was less common ( $11 \%$ of live stems), but dominated snag populations ( $54 \%$ of snags, $48 \%$ of snag basal area). Ten additional tree species (eight coniferous and two broadleaved species) comprised the remaining $6 \%$ of stems (Table 1); among these, Abies procera and Pseudotsuga menziesii were the most common species.

Trees invaded meadows at Bunchgrass Ridge during two broad, but distinct periods, but at much greater density during the more recent period (Fig. 1a). Temporal patterns were very similar among
Table 1. Characteristics of live trees $(\geq 1.4-\mathrm{m}$ tall), seedlings (0.1-1.4-m tall), and snags ( $\geq 5-\mathrm{cm} \mathrm{dbh})$ in the three mapped plots. Plot 1 is 2 ha and plots 2 and 3 are 1 ha each; means are weighted by plot area. "Other species" include Abies amabilis, A, procera, Castanopsis chrysophylla, Libocedrus decurrens, Pinus monticola, Pseudotsuga menziesii, Rhamnus purshiana, Taxus brevifolia, Tsuga heterophylla, and Tsuga mertensiana.

\begin{tabular}{|c|c|c|c|c|}
\hline & Plot 1 & Plot 2 & Plot 3 & Mean \\
\hline \multicolumn{5}{|c|}{ Density of live trees $\left(\right.$ no. ha ${ }^{-1}$ ) } \\
\hline A. grandis & 1260 & 1005 & 1046 & 1143 \\
\hline P. contorta & 171 & 89 & 158 & 147 \\
\hline Other species & 72 & 92 & 91 & 81 \\
\hline \multicolumn{5}{|c|}{ Density of seedlings (no. ha ${ }^{-1}$ ) } \\
\hline A. grandis & 3516 & 1875 & 3867 & 3193 \\
\hline P. contorta & 59 & 0 & 0 & 29 \\
\hline Other species & 156 & 39 & 234 & 147 \\
\hline \multicolumn{5}{|c|}{ Basal area of live trees $\left(\mathrm{m}^{2} \mathrm{ha}^{-1}\right)$} \\
\hline A. grandis & 32.4 & 42.1 & 37.1 & 36.0 \\
\hline P. contorta & 6.2 & 2.4 & 4.6 & 4.9 \\
\hline Other species & 2.1 & 1.3 & 1.6 & 1.8 \\
\hline \multicolumn{5}{|c|}{ Density of snags (no. ha ${ }^{-1}$ ) } \\
\hline A. grandis & 128 & 135 & 244 & 159 \\
\hline P. contorta & 179 & 92 & 299 & 187 \\
\hline Other species & 0 & 1 & 1 & $<1$ \\
\hline \multicolumn{5}{|c|}{ Basal area of snags $\left(\mathrm{m}^{2} \mathrm{ha}^{-1}\right)$} \\
\hline A. grandis & 9.5 & 6.2 & 3.8 & 7.3 \\
\hline P. contorta & 6.3 & 4.6 & 10.2 & 6.8 \\
\hline Other species & 0.0 & $<0.1$ & $<0.1$ & $<0.1$ \\
\hline
\end{tabular}

plots, thus we present a composite age structure for the full 4-ha sample area. Few live $P$. contorta (3.2 stems ha ${ }^{-1}$ ) survived from the first period of invasion (Fig. 1a, insert). However, many $\left(19 \mathrm{ha}^{-1}\right)$ were present as large $(>37-\mathrm{cm} \mathrm{dbh})$ snags and are absent from the age structure (Fig. 1a). Similarly, no live $P$. contorta dated from 1900 to 1930 (onset of the second wave of invasion), although many from this period were present as snags (Table 1). Peak establishment of P. contorta (1940-1945) preceded the peak in A. grandis (1955-1960).

Abies grandis dominated both periods of invasion: establishment increased steadily from the early 1800s (Fig. 1a, inset) to peak at ca. 1875, then declined. Few trees established between 1900 and 1920, but rates of establishment rose steeply through 1955-1960, then declined steeply. The apparent lack of establishment after ca. 1985 is, in part, an artifact of the minimum height $(1.4 \mathrm{~m})$ of aged stems; smaller, younger $A$. grandis were present in the forest understory (Table 1). In contrast, the absence of younger $P$. contorta, which has rapid juvenile growth, is not a sampling artifact.

\section{Temporal correlations with climate}

The broad, smooth, humped-shaped distribution of tree establishment during the past century showed little correspondence to climatic variation 

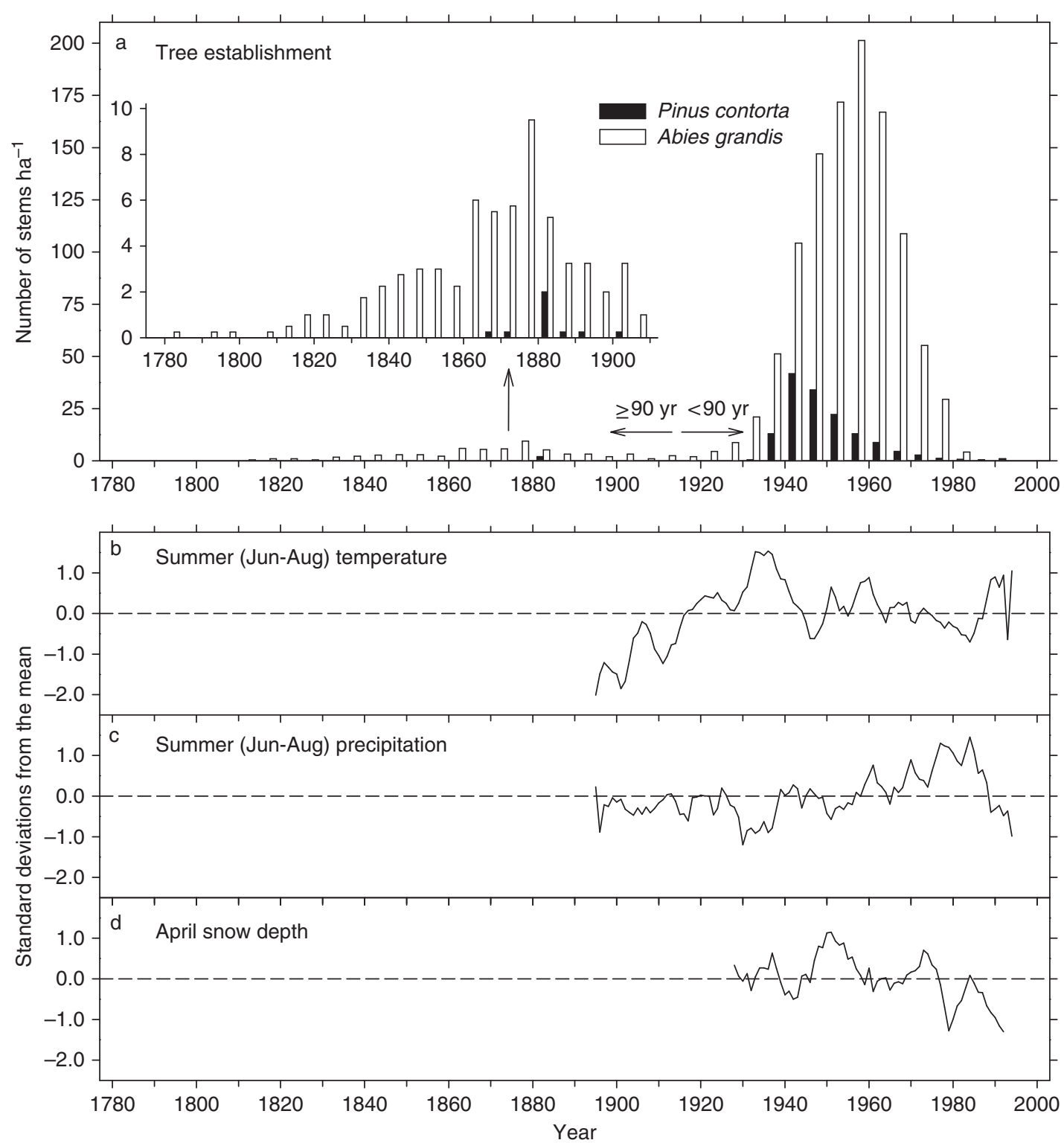

Fig. 1. (a) Temporal trends in the establishment of Abies grandis and Pinus contorta (live trees $\geq 1.4$-m tall; all plots combined) and (b-d) temporal variation in selected climatic variables (expressed as standard deviations from the mean). Dates of establishment are mid-points of 5-yr age classes. The initial period of invasion (1780-1910) is enlarged for clarity; many $P$. contorta persisting as large snags $(>37-\mathrm{cm} \mathrm{dbh})$ are missing from this portion of the age structure $\left(19 \mathrm{snags} \mathrm{ha}^{-1} \mathrm{vs}^{2} .2\right.$ live stems ha ${ }^{-1}$; see Results).

(Fig. 1). For neither tree species was density correlated with summer temperature or precipitation $(r=-0.03$ to 0.29 ; all $P>0.22)$. Onset of invasion (ca. 1920-1930) coincided with a period of aboveaverage temperature and average to below-average precipitation; invasion then increased rapidly during the warmest, driest decade on record (1930-1940, Fig. 1b, c). Declining rates of establishment after 1960 occurred during a period of average to cool temperatures (Fig. 1b) and above-average precipitation (Fig. 1c), although climatic trends during these decades were highly variable. Correlations with April snowpack were not significant for $P$. contorta $(r=0.28, P=1.0)$ and only marginally significant for $A$. grandis $(r=0.50, P=0.07)$.

\section{Univariate spatial patterns of association}

For most (nine of 12) univariate tests, we detected strong spatial aggregation of stems at most distances (Fig. 3). Young (<90 yr) P. contorta were strongly clumped at nearly all distances in all plots 

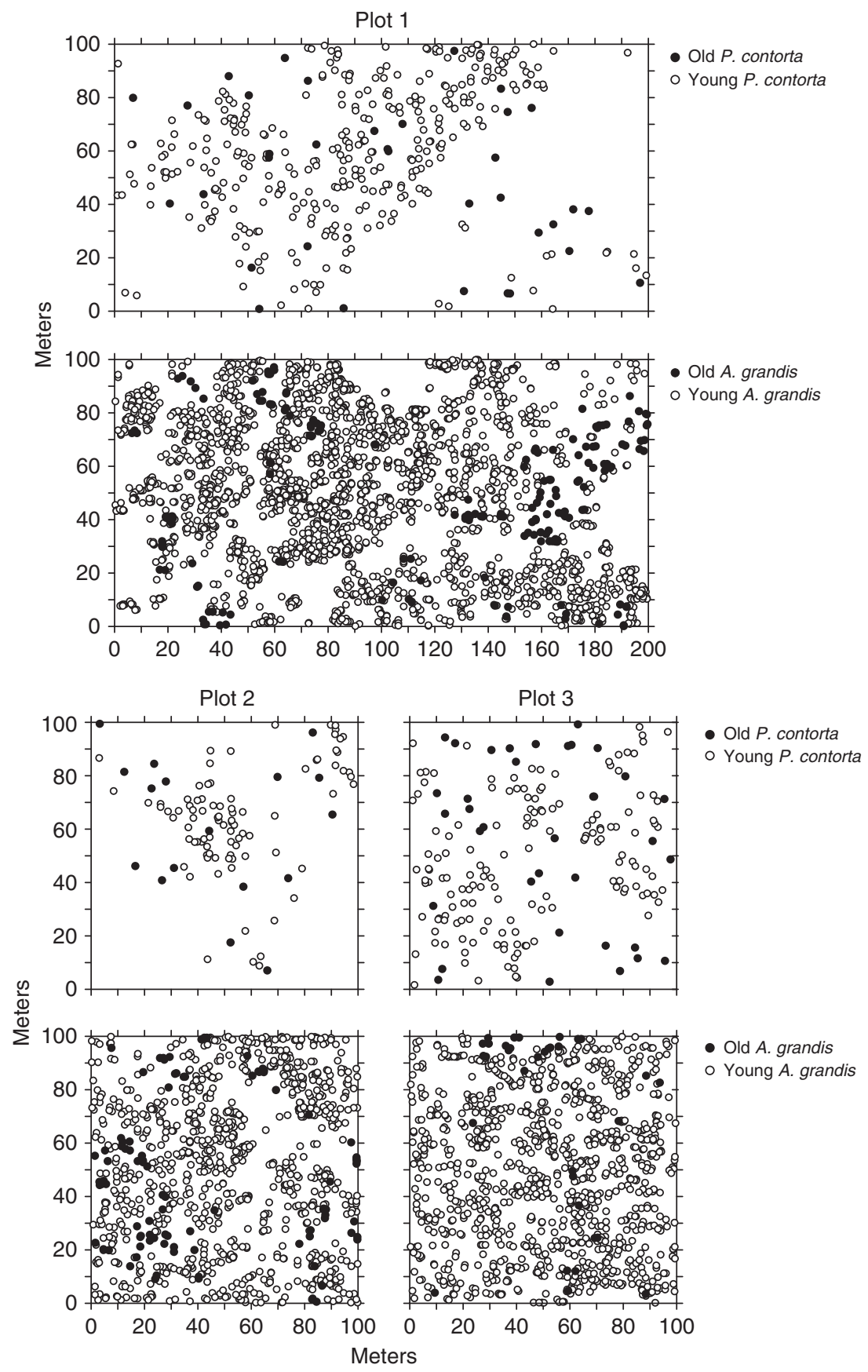

Fig. 2. Spatial distributions of young $(<90 \mathrm{yr})$ and old $(\geq 90 \mathrm{yr})$ stems of Pinus contorta and Abies grandis in each of the three plots. Trees diameters are not to scale.

(Fig. 3b). Old $A$. grandis were strongly clumped at all distances in plots 1 and 2, but not at short distances $(<1 \mathrm{~m})$ in plot 3 , where density was low (Fig. 3c). Young A. grandis showed strong clumping at most distances in plots 1 and 2 , but weaker clumping at short to intermediate distances $(<10 \mathrm{~m})$ in plot 3 (Fig. 3d). Old ( $\geq 90 \mathrm{yr}$ ) P. contorta were the exception to these trends: stems did not deviate significantly from random (Fig. 3a), although densities were low (17-36 stems ha ${ }^{-1}$; Figs. 2 and 3) limiting our ability to detect pattern.

\section{Bivariate spatial patterns of association}

In contrast to the dominance of aggregation among univariate tests, bivariate tests revealed a diversity of patterns (Fig. 4). Within species, young and old $P$. contorta showed strong negative associa- 


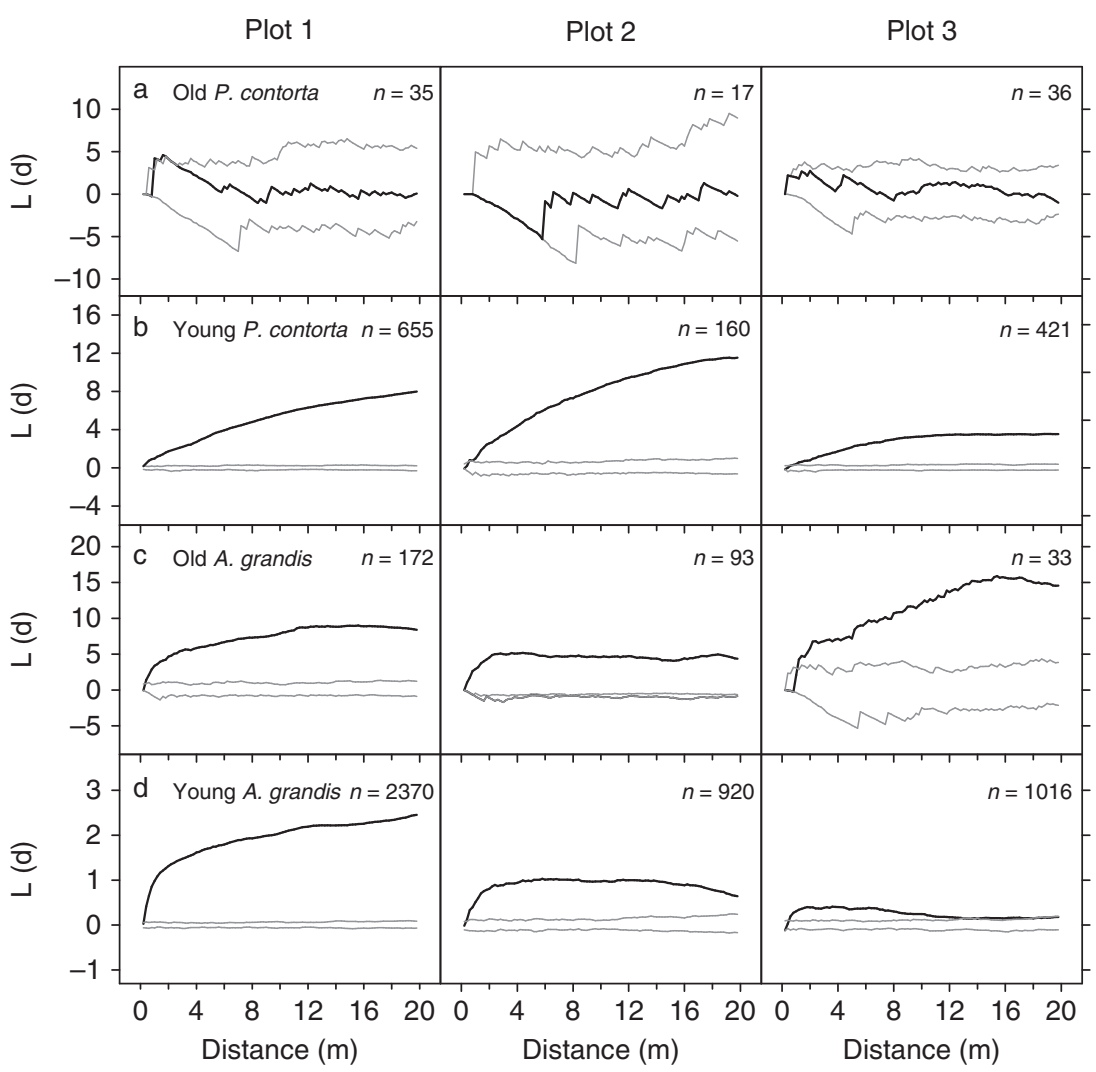

Fig. 3. Univariate spatial distributions, $L(d)$ vs $d$, and confidence envelopes for (a) old ( $\geq 90 \mathrm{yr}$ ) P. contorta, (b) young ( $<90 \mathrm{yr}$ ) $P$. contorta, (c) old $A$. grandis, and (d) young $A$. grandis in each of the three plots. Values of $L(d)$ outside the confidence envelope indicate significant departures from random: aggregation if above and repulsion if below the envelope. $n=$ number of trees.

tions (spatial displacement) at all distances in plot 3 , but varying patterns of association in plots 1 and 2 (Figs. 2 and $4 \mathrm{a}$ ). Young and old A. grandis also showed strong negative associations at most distances in plots 1 and 2 (Fig. 4b), but no association in plot 3 . In contrast, spatial associations between species were largely positive (Figs. 4c-f). Old $P$. contorta and old $A$. grandis were positively associated at varying distances in plots 1 and 3 , but not in plot 2 , where $P$. contorta was sparse (Fig. 4c). Young $P$. contorta and young $A$. grandis showed strong positive associations at all spatial scales in plots 1 and 2, but only at short distances (ca. $<2 \mathrm{~m}$ ) in plot 3 (Fig. 4d). Young $A$. grandis were positively associated with old $P$. contorta in plot 1 (at all distances) and in plot 3 (to ca. $6 \mathrm{~m}$ ), but not in plot 2 (Fig. 4e). Only young $P$. contorta and old $A$. grandis showed a strong negative association at most distances (Fig. 4f).

\section{Invasion dynamics}

The time-series of stem maps revealed aspects of the invasion process that were not discernable from the age structure or spatial analyses (Fig. 5). In 1915, prior to $20^{\text {th }}$ century encroachment, tree populations were sparse, comprised of scattered individuals of $P$. contorta and widely distributed clumps of A. grandis of varying size, shape, and connectivity. Despite the low density of trees, most areas of meadow fell within $20 \mathrm{~m}$ of a potential seed source (1915 panel, Fig. 5). Massive invasion during the next three decades (by 1945) greatly reduced the area of open meadow, a pattern that intensified during the next $15 \mathrm{yr}$ (by 1960). The boundaries of any remaining meadow openings changed little during the last four decades (to 2004).

Two processes in particular contributed to these changes: (1) colonization of larger meadow openings by individuals or groups of trees leading to significant infilling (1915-1945), and (2) establishment within smaller openings among irregularly shaped patches of A. grandis leading to coalescence of these clumps (1945-1960) (Fig. 5). A third process, establishment beneath scattered old $P$. contorta, also occurred in plots 1 and 3; however, its spatial extent was limited by the low density of old stems. 


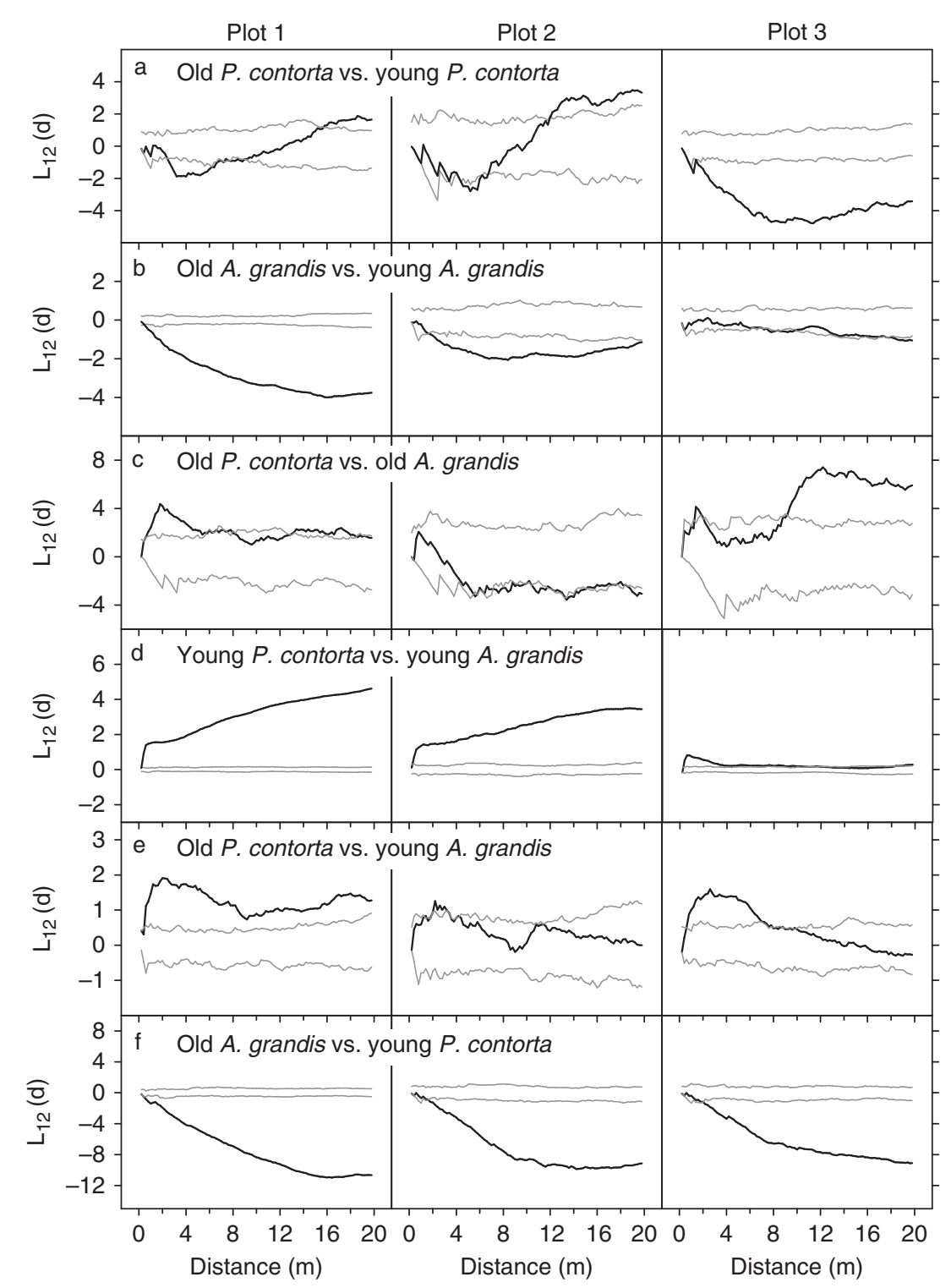

Fig. 4. Bivariate spatial associations, $L_{12}(d)$ vs $d$, and confidence envelopes for different species and/or age classes in each of the three plots: (a) old vs young $P$. contorta, (b) old vs young $A$. grandis, (c) old $P$. contorta vs old $A$. grandis, (d) young $P$. contorta vs young $A$. grandis, (e) old $P$. contorta vs young $A$. grandis, and (f) old $A$. grandis vs young $P$. contorta. See Fig. 3 for sample sizes and other details.

P. contorta and A. grandis contributed differently to these processes. P. contorta preferentially colonized areas of open meadow (1945 panels, Fig. 5); it rarely established within or adjacent to existing tree clumps. A. grandis played a diversity of roles, recruiting beneath scattered old $P$. contorta (1945 panels, Fig. 5), into smaller openings among older forest patches (1945 and 1960 panels, Fig. 5), and into larger meadows into which $P$. contorta had previously established (1960 panels, Fig. 5).

\section{Discussion}

The processes that contribute to encroachment of grasslands and meadows by woody plants are of global relevance and have been studied from a diversity of perspectives. Inferring process from pattern can be challenging, however, when tree invasions and forest development span many decades or centuries. Previous studies have sought explanations for recent invasions largely among exogenous factors (i.e., changes in climate, grazing 

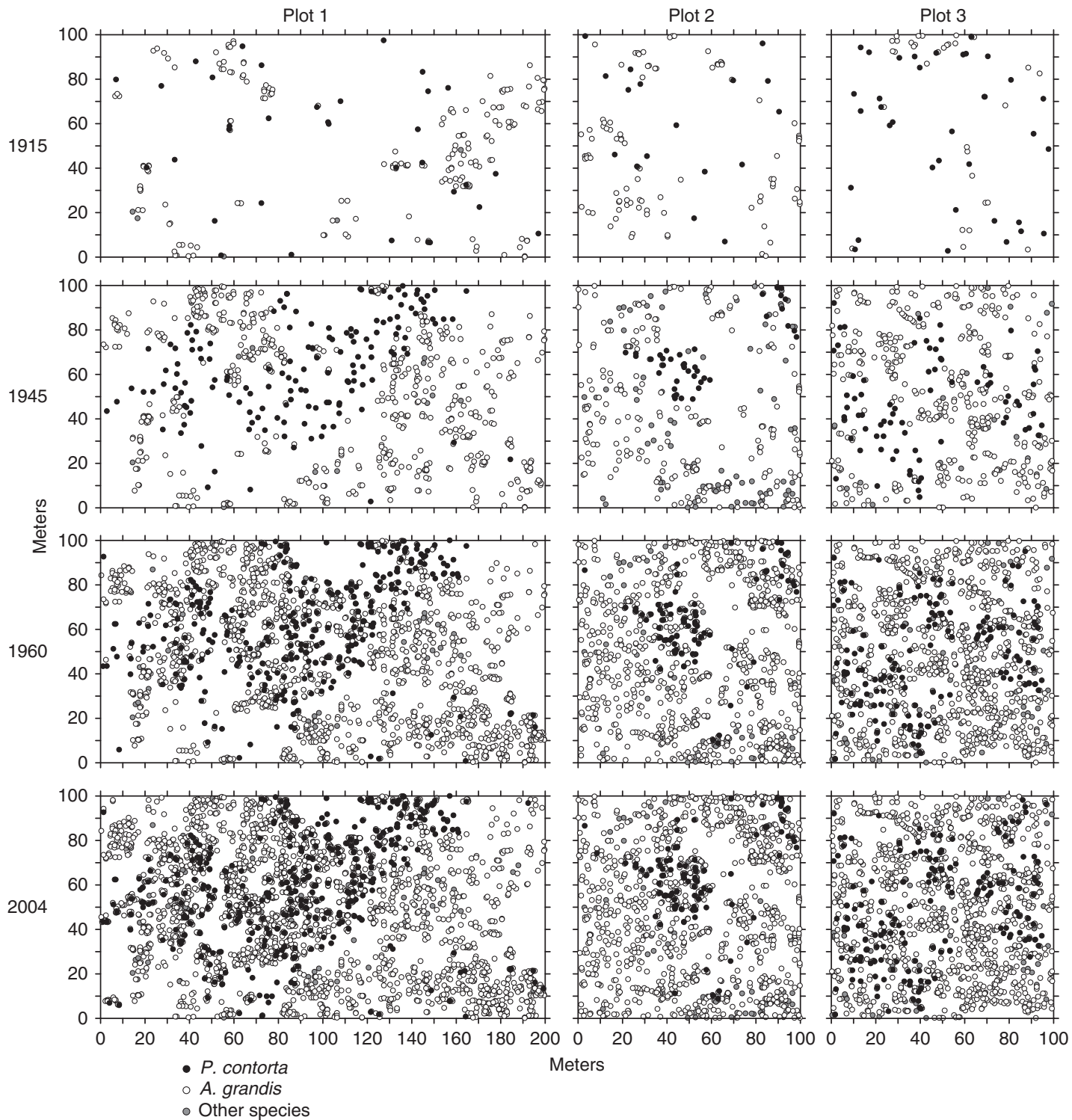

Fig. 5. Stem maps illustrating the temporal sequence of invasion in each of the three plots. Large snags meeting the size criteria for "old stems" ( $\geq 90 \mathrm{yr}$; see Analysis) are included in the 1915 maps for consistency with spatial point pattern analyses. Tree diameters are not to scale.

pressure, or fire frequency) that permit establishment of woody plants where they have previously been excluded. We suggest that a more complete understanding of the invasion processes can be gained by considering both the spatial and temporal patterns of tree establishment. We combine evidence from the age structures and spatial distributions of tree species to demonstrate that recent invasion of meadows at Bunchgrass Ridge, although possibly triggered by a change in disturbance regime, is a complex consequence of past invasions, biotic interactions, and the life histories of the species.

\section{Temporal trends in invasion and correlations} with climate

Trees have invaded meadows at Bunchgrass Ridge for at least two centuries, although establishment has been highly structured in time. Age distributions indicate establishment during two broad periods, each spanning many decades but differing in intensity, with $P$. contorta and $A$. grandis exhibiting hump-shaped, but non-synchronous, increases and declines. Establishment was not episodic, as might occur if it were driven by cyclical patterns of cone production (1-3-yr intervals in these 
species; Foiles et al. 1990; Lotan \& Critchfield 1990), or by short windows of opportunity as in some systems (Dovčiak et al. 2005; League \& Veblen 2006). Nor was establishment chronic, with continuous, but low rates of recruitment (e.g., Peters et al. 2006). Temporal patterns similar to those at Bunchgrass Ridge have been documented in other mountain grasslands in western North America, although the onset and intensity of invasion have differed among systems (Franklin et al. 1971; Dunwiddie 1977; Magee \& Antos 1992; Jakubos \& Romme 1993; Miller \& Halpern 1998; Norman \& Taylor 2005; Coop \& Givnish 2007).

The sudden advance of trees into grasslands or meadows is often attributed to a change in climate or disturbance regime that alters the competitive balance between tree seedlings and herbaceous vegetation (e.g., Rochefort et al. 1994; Scholes \& Archer 1997; Van Auken 2000). Although one or more extrinsic factors are likely to have triggered invasions at Bunchgrass, none can explain the temporal patterns of establishment sustained over multiple decades. Establishment rates during the 20th century, the period for which we have reliable weather records, showed little relationship to summer temperature or precipitation. Moreover, invasion accelerated during a period of warmer, drier summers and declined during cooler, wetter summers. These trends run counter to our understanding of the relationship between summer drought and tree seedling mortality and to invasion patterns in dry-site meadows elsewhere this region (Vale 1981; Miller \& Halpern 1998). Although establishment of $A$. grandis showed a marginally significant correlation with spring snowpack, the overall correspondence was quite poor.

Historical human activities clearly have a major influence on the dynamics of tree establishment in many systems (e.g., Motta \& Nola 2001; Vittoz et al. 2008), but ascertaining their role at Bunchgrass Ridge is difficult because precise historical information is lacking. Changes in disturbance regime could have triggered invasion (Vale 1981; Miller \& Halpern 1998; Norman \& Taylor 2005), although direct evidence is lacking. Native Americans, and subsequently, European settlers used fire to maintain meadow openings, but these activities are poorly documented (Burke 1979; Boyd 1999; Hadley 1999). Fire suppression (initiated in the early 1900s in this region) has been highly effective (Burke 1979; Weisberg \& Swanson 2003). The lack of fire scars on large trees and stumps suggests that Bunchgrass Ridge has not burned for a century or more, although low-intensity fires limited to meadow openings could have removed tree seedlings without scarring larger trees. Thus, fire could have been important in the historical maintenance of these meadows, and reduction of fire (elimination of aboriginal burning, suppression of wildfire) could have triggered the onset of invasion. However, fire is unlikely to be relevant to subsequent patterns of tree establishment, which is the focus of this study.

Cessation of grazing by sheep could also have triggered 20th century invasion. Federal grazing allotments in the western Cascades were terminated between 1918 and 1947 (Elliot 1946; Johnson 1985), a period that encompasses the onset of invasion at Bunchgrass Ridge. However, in the absence of more definitive historical information, we can only speculate about the ways in which climate or changes in disturbance may have contributed to the early stages of invasion at Bunchgrass Ridge. Regardless, the hump-shaped population age structure spanning many decades of establishment is inconsistent with a process driven by climatic variation or disturbance alone. Rather, it suggests a two-phase model in which removal of a limiting factor initiated a longerterm process shaped, in large part, by biotic interactions. The importance of these biotic interactions would be difficult to infer in the absence of spatiotemporal data.

\section{Spatial structure of invading trees}

In combination, soil profiles, stem maps, and the composite age structure suggest that, at the beginning of the 20th century, Bunchgrass Ridge was primarily meadow, supporting only widely scattered individuals or clumps of trees. Although few $P$. contorta survived from the initial period of invasion (mid- to late-1800s), stem maps and univariate analysis, which include large old snags, indicate a broad dispersion of stems. In contrast, old A. grandis showed pronounced spatial aggregation, forming tree islands of varying size and shape, often associated with old $P$. contorta. The factors that constrained the density or spatial extent of these early invasions remain unclear; however, the resulting spatial structure appears to have predisposed the system to rapid invasion during the 20th century.

Young ( $<90 \mathrm{yr}$ ) stems of both species, comprising the more recent wave of invasion, showed pronounced aggregation over a broad range of spatial scales, forming new patches of varying size, shape, and composition among older patches of A. grandis. This aggregation resulted, in large part, from two processes both enabled by the legacy of past invasions. Larger meadow openings were primarily colonized by $P$. contorta from seed sources 
widely distributed through the plots, then increasingly by $A$. grandis. This resulted in substantial loss of meadow habitat. In contrast, smaller openings between older patches of forest were colonized directly by $A$. grandis. In these areas, $A$. grandis likely benefited from the complex geometry of the forestmeadow mosaic that placed most openings $<20 \mathrm{~m}$ from an edge, close to seed sources, and within the zones of influence (shading and possible mycorrhizal effects) of neighboring trees (Dickie et al. 2005; Griffiths et al. 2005). Unlike many systems, however, we did not observe progressive encroachment from the forest edge (e.g., Magee \& Antos 1992; Coop \& Givnish 2007; Dovčiak et al. 2008). This process may be more common where meadows are large, or where the primary constraint on establishment is competition with dense herbaceous vegetation and suppression of this vegetation occurs only along the forest edge.

In contrast to these patterns of aggregation, young $P$. contorta and $A$. grandis showed strong spatial displacement from old $A$. grandis. This is not surprising for $P$. contorta given its intolerance of shade. However, for A. grandis, which is tolerant of a broader range of light conditions, it suggests a more complex dynamic. Although present in the understory of older forest patches, A. grandis regenerated at considerably greater density in adjacent meadow openings. As in many forests where tree regeneration is concentrated in canopy gaps (Runkle 1981; Brokaw 1985), small meadow openings may offer favorable conditions for establishment little competition from trees immediately above, but a modified microclimate compared to larger openings. In contrast, under older forests, competition from canopy trees and dense communities of forest herbs may limit establishment and growth.

\section{Evidence of biotic interactions and the contrasting roles of $P$. contorta and $A$. grandis}

Clearly, inferring biotic interaction from spatial pattern requires caution. Positive associations could be explained by facilitation, but also by similar patterns of dispersal or responses to environment. Likewise, negative associations could indicate inhibition or competition, but also contrasting responses to a heterogeneous environment or indirect effects mediated by another species. Species life histories, relative timing of establishment, environmental context, and spatial scale are important considerations in distinguishing among these alternatives.

Several explanations are possible for the pronounced aggregation of young, conspecific stems over a broad range of spatial scales. For both species, clumping could reflect proximity to parent trees (driven by seed dispersal), but this is not supported by the results of bivariate analyses. Young stems either showed pronounced spatial displacement from older conspecific stems, no association, or occasionally, clumping at larger distances (>12-16 m). Aggregation of young $P$. contorta, a species that requires full sun to regenerate (Lotan \& Critchfield 1990), appears related to the spatial distribution and size of meadow openings, legacies of previous invasion. Abundant regeneration within these openings was ensured by the broad dispersion of parent trees: most areas of meadow were within $20-30 \mathrm{~m}$ of the nearest seed source (1915 panel, Fig. 5), well within the range of abundant seed rain (Lotan \& Critchfield 1990).

Not only were young conspecific stems spatially aggregated, so too were young stems of $P$. contorta and A. grandis. Spatial coincidence of these species could reflect similar patterns of dispersal, but this is unlikely given the contrasting distributions of parent trees (widely dispersed in P. contorta vs locally clumped in A. grandis). Alternatively, it could reflect heterogeneity of site conditions, with regeneration of both species limited to the same types of microsites. However, this seems improbable given the autecological differences between species (Foiles et al. 1990; Lotan \& Critchfield 1990), and the uniformity of topography, soils, and vegetation. In combination, two sources of evidence temporal and spatial - point to facilitation as a likely mechanism for the positive association of young $P$. contorta and A. grandis. First, the peak in A. grandis establishment followed soon after that of $P$. contorta. Second, bivariate analyses indicated a strong positive association at small spatial scales $(<1 \mathrm{~m})$, the scales over which facilitative effects (e.g., shading by neighboring trees) are likely to be strongest. Positive associations also were observed between old stems (or large snags) of $P$. contorta and young or old stems of $A$. grandis. Thus, although $P$. contorta was numerically less important than A. grandis, its ability to establish in large meadow openings and form new foci for recruitment appears important in the invasion process. Nucleation, in which a woody pioneer facilitates subsequent tree establishment, has been observed in grassland invasions (e.g., Duarte et al. 2006) and other systems (e.g., pastures and old fields) although the mechanisms responsible for positive feedbacks may differ (e.g., trees can serve as perches for seed-dispersing birds; Debussche \& Lepart 1992; Pausas et al. 2006).

Facilitation by conspecific stems of $A$. grandis is also likely to have contributed to rapid infilling of meadow openings. Not only were young stems strongly clumped at small distances, but rates of 
establishment increased dramatically (by an order of magnitude) between 1920 and 1960, suggesting a positive feedback, with greater numbers of stems or larger/older individuals increasing the likelihood of subsequent recruitment. Facilitation can occur through moderation of microclimatic stress (Belsky et al. 1989; Pugnaire et al. 2004), suppression of competing meadow vegetation (Magee \& Antos 1992; Kunstler et al. 2006), or the cumulative effects of trees on soil properties (Amiotti et al. 2000; Siemann \& Rogers 2003; Griffiths et al. 2005). Temporal trends and local densities within these patches - many times greater than the average density of ca. 1100 stems ha $^{-1}$ (Table 1) - suggest that after 1960, a density threshold may have been reached. Rates of establishment subsequently declined, indicative of a shift from facilitative to competitive effects (Dickie et al. 2005), with further establishment or survival limited by preemption of space or resources. The negative association of young and old $A$. grandis suggests that these competitive effects may persist, shaping the longer-term development of these forests. Similar shifts over time in the balance of positive and negative effects have been observed between nurse and protégé plants as a result of ontogenetic processes (Miriti 2006; Reisman-Berman 2007). In this system, a shift from facilitation by young conspecific stems of $A$. grandis in meadow openings to competitive inhibition of seedlings in older stands has important consequences for the rate and pattern of vegetation change - initially, by accelerating the pace at which forests replace meadows, and subsequently, by slowing the structural (subcanopy) development of older forests.

Facilitative interactions in which benefactor and beneficiary are different tree species highlight the importance of life history and functional traits in structuring invasions (Archer et al. 1988; Callaway \& Walker 1997; Baumeister \& Callaway 2006; Duarte et al. 2006). Tree species differ in their abilities to invade and subsequently modify their surrounding environments (e.g., Siemann \& Rogers 2003; Haugo \& Halpern 2010) - differences that reflect inherent life-history tradeoffs, as well as morphological and physiological traits (Huston $\&$ Smith 1987). As a result, the spatial and temporal dynamics of invasion can vary with the characteristics of the invading species (e.g., Moore \& Huffman 2004). Invasions at Bunchgrass Ridge would have been greatly tempered in time and space in the absence of either $P$. contorta or A. grandis. When species with contrasting life histories and functional roles are present, synergistic interactions are possible that can foster rapid conversion of meadow to forest.

\section{Dynamics of the forest-grassland ecotone}

Woody plant invasions in these and other grassland ecosystems defy simple causal explanations. Nevertheless, the ecotones that separate woody and herbaceous communities can be viewed as dynamic tension zones (Carpenter 1935; van der Maarel 1990) shaped by opposing sets of influences that vary in time, causing fluctuations or directional changes between alternative vegetation states (e.g., Beckage \& Ellingwood 2008). One set inhibits establishment or preferentially removes woody plants (through disturbances such as fire or grazing); the other set promotes establishment and persistence of trees (through asymmetric competition with herbaceous plants or alteration of soil properties). Long-term persistence of herbaceous communities in the face of invasion pressure suggests that, historically, factors that inhibited woody plant establishment (e.g., competition with dense communities of graminoids or herbs, or periodic burning) were more effective than those that promoted it. Recent invasions at a global scale point to a fundamental reversal of this balance. Our study illustrates that once invasions are initiated, facilitation and positive feedbacks can promote rapid conversion of meadow to forest. That establishment of $A$. grandis accelerated at a time when climatic conditions were less than optimal for early survival dispels the notion of a simple relationship between climate and tree recruitment, and underscores the challenge of predicting future variation in the face of climate change. Understanding the role of biotic interactions is critical to modeling future changes, and to maintaining or restoring the natural dynamics of these and other forest-grassland mosaics.

Acknowledgements. For field assistance we thank Michael Frank, James Freund, Marcus Koch, Jennifer Leach, James Lutz, Jessica Niederer, Kyle Smith, Florian Steer, Katrin Wendt, and Tina Völkl. Ziyu Ma assisted with tree-ring counts. Duane Lammers and Ted Dyrness described soil profiles. Jon Bakker, Marcela Bustamante-Sánchez, Martin Dovčiak, Chad Jones, Fred Swanson, and three anonymous reviewers provided helpful comments on earlier drafts of this paper. Cheryl Friesen (Willamette National Forest) and numerous staff from the McKenzie River Ranger District (USFS) provided logistical support. Funding was provided by the Joint Fire Science Program (agreement no. 1422RAH03-0021). JMR was supported by an NSF IGERT Ecosystem Informatics Fellowship (NSF DGE0333257). 


\section{References}

Amiotti, N.M., Zalba, P., Sanchez, L.F. \& Peinemann, N. 2000. The impact of single tree properties of loessderived grassland soils in Argentina. Ecology 81: 3283-3290.

Anonymous. 1990. World WeatherDisc. Version 2.0. WeatherDisc Associates Inc., Seattle, WA, US.

Archer, S., Scifres, C., Bassham, C.R. \& Maggio, R. 1988. Autogenic succession in a subtropical savanna: conversion of grassland to thorn woodland. Ecological Monographs 58: 111-127.

Baumeister, D. \& Callaway, R.M. 2006. Facilitation by Pinus flexilis during succession: a hierarchy of mechanisms benefits other plant species. Ecology 87: 1816-1830.

Beckage, B. \& Ellingwood, C. 2008. Fire feedbacks with vegetation and alternative stable states. Complex Systems 18: 159-173.

Belsky, A.J., Amundson, R.G., Duxbury, J.M., Riha, S.J., Ali, A.R. \& Mwonga, S.M. 1989. The effects of trees on the physical, chemical and biological environments in a semi-arid savanna in Kenya. Journal of Applied Ecology 26: 1005-1024.

Bond, W.J. \& Midgley, G.F. 2000. A proposed $\mathrm{CO}_{2-}$ controlled mechanism of woody plant invasion in grasslands and savannas. Global Change Biology 6: 865-869.

Boulant, N., Kuntsler, G., Rambal, S. \& Lepart, J. 2008. Seed supply, drought, and grazing determine spatiotemporal patterns of recruitment for native and introduced invasive pines in grasslands. Diversity and Distributions 14: 862-874.

Boyd, R. 1999. Indians, fire, and the land in the Pacific Northwest. Oregon State University Press, Corvallis, OR, US.

Brokaw, N.V.L. 1985. Gap-phase regeneration in a tropical forest. Ecology 66: 682-687.

Browning, D.M., Archer, S.R., Asner, G.P., McClaran, M.P. \& Wessman, C.A. 2008. Woody plants in grasslands: post-encroachment stand dynamics. Ecological Applications 18: 928-944.

Burke, C.J. 1979. Historic fires in the central western Cascades, Oregon. M.Sc. Thesis, Oregon State University, Corvallis, OR, US.

Callaway, R.M. 1998. Are positive interactions speciesspecific? Oikos 82: 2020-2207.

Callaway, R.M. \& Walker, L.R. 1997. Competition and facilitation: a synthetic approach to interactions in plant communities. Ecology 78: 1958-1965.

Carpenter, J.R. 1935. Fluctuations in biotic communities. I. Prairie-forest ecotone of central Illinois. Ecology 16: 203-212.

Cline, S.P., Berg, A. \& Wight, H. 1980. Snag characteristics and dynamics in Douglas-fir forests, western Oregon. Journal of Wildlife Management 44: 773-787.

Coop, J.D. \& Givnish, T.J. 2007. Spatial and temporal patterns of recent forest encroachment in montane grasslands of the Valles Caldera, New Mexico, USA. Journal of Biogeography 34: 914-927.

Coop, J.D. \& Givnish, T.J. 2008. Constraints on tree seedling establishment in montane grasslands of the Valles Caldera, New Mexico. Ecology 89: 1101-1111.

Debussche , M. \& Lepart, J. 1992. Establishment of woody plants in Mediterranean old fields: opportunity in space and time. Landscape Ecology 6: 133-145.

Dickie, I.A., Schnitzer, S.A., Reich, P.B. \& Hobbie, S.E. 2005. Spatially disjunct effects of co-occurring competition and facilitation. Ecology Letters 8: 1191-1200.

Dovčiak, M., Frelich, L.E. \& Reich, P.B. 2005. Pathways in old-field succession to white-pine: seed rain, shade, and climate effects. Ecological Monographs 75: 363-378.

Dovčiak, M., Hrivnák, R., Ujházy, K. \& Gőmőry, D. 2008. Seed rain and environmental controls on invasion of Picea abies into grassland. Plant Ecology 194: 135-148.

Dunwiddie, P.W. 1977. Recent tree invasion of subalpine meadows in the Wind River Mountains, Wyoming. Arctic and Alpine Research 9: 393-399.

Duarte, L.S., Machado, R.E., Hartz, S.M. \& Pillar, V.D. 2006. What saplings can tell us about forest expansion over natural grasslands. Journal of Vegetation Science 17: 799-808.

Elliot, R.A. 1946. Grazing policy statement, 5-year period 1946-1950. Willamette National Forest supplement to the forest grazing plan. Supervisor's Office, Willamette National Forest, USDA Forest Service, Eugene, OR, US.

Foiles, M.W., Graham, R.T. \& Olson Jr., D.F. 1990. Abies grandis (Dougl. ex. D. Don) Lindl. Grand Fir. In: Burns, R.M. \& Honkala, B.H. (tech. coords.) Silvics of North America: 1. Conifers. pp. 80-96. Agriculture Handbook 654, USDA Forest Service, Washington, DC, US.

Franklin, J.F. \& Halpern, C.B. 1999. Pacific Northwest forests. In: Barbour, M.G. \& Billings, W.D. (eds.) North American terrestrial vegetation. 2nd ed., pp. 123-159. Cambridge University Press, New York, NY, US.

Franklin, J.F., Moir, W.H., Douglas, G.W. \& Wiberg, C. 1971. Invasion of subalpine meadows by trees in the Cascade Range, Washington and Oregon. Arctic and Alpine Research 3: 215-224.

Goreaud, F. \& Pelissier, R. 2003. Avoiding misinterpretation of biotic interactions with the intertype $K_{12}$-function: population independence vs. random labeling hypotheses. Journal of Vegetation Science 14: 681-692.

Griffiths, R., Madritch, M. \& Swanson, A. 2005. Conifer invasion of forest meadows transforms soil characteristics in the Pacific Northwest. Forest Ecology and Management 208: 347-358.

Hadley, K.S. 1999. Forest history and meadow invasion at the Rigdon Meadows Archaeological site, western Cascades, Oregon. Physical Geography 20: 116-133.

Haugo, R.D. \& Halpern, C.B. 2007. Vegetation responses to conifer encroachment in a western Cascade meadow: 
a chronosequence approach. Canadian Journal of Botany 85: 285-298.

Haugo, R.D. \& Halpern, C.B. 2010. Tree age and tree species shape positive and negative interactions in a montane meadow. Botany 88: 488-499.

Heyerdahl, E.K., Miller, R.F \& Parsons, R.A. 2006. History of fire and Douglas-fir establishment in a savanna and sagebrush-grassland mosaic, southwestern Montana, USA. Forest Ecology and Management 230: 107-118.

Hibbard, K.A., Archer, S., Schimel, D.S. \& Valentine, D.W. 2001. Biogeochemical changes accompanying woody plant encroachment in a subtropical savanna. Ecology 82: 1999-2011.

Hitchcock, C.L. \& Cronquist, A. 1973. Flora of the Pacific Northwest. University of Washington Press, Seattle, WA, US.

Huston, M. \& Smith, T. 1987. Plant succession: life history and competition. The American Naturalist 130: 168-198.

Jackson, R.B., Banner, J.L., Jobbágy, E.G., Pockman, W.T. \& Wall, D.H. 2002. Ecosystem carbon loss with woody plant invasion of grasslands. Nature 418: 623-626.

Jakubos, B. \& Romme, W.H. 1993. Invasion of sub-alpine meadows by lodgepole pine in Yellowstone National Park, Wyoming, USA. Arctic and Alpine Research 25: 382-390.

Johnson, R.R. 1985. Historical records inventory for the Willamette National Forest: forest grazing permits. Forest Service Warehouse, USDA Forest Service, Willamette National Forest, Eugene, OR, US.

Joint Fire Science Program. 2009. Restoring mountain meadows: using fire, vegetation, and fuel management in western Oregon. Fire Science Brief 75: 1-6. (http:// www.firescience.gov/projects/01C-3-3-10/supdocs/01C3-3-10_fsbrief75-final.pdf).

Jurena, P.N. \& Archer, S. 2003. Woody plant establishment and spatial heterogeneity in grasslands. Ecology 84: 907-919.

Kennedy, P.G. \& Sousa, W.P. 2006. Forest encroachment into a Californian grassland: examining the simultaneous effects of facilitation and competition on tree seedling recruitment. Oecologia 148: $464-474$.

Kunstler, G., Thomas, C., Bouchaud, M. \& Lepart, J. 2006. Indirect facilitation and competition in tree species colonization of sub-Mediterranean grasslands. Journal of Vegetation Science 17: 379-388.

Lang, N.L. \& Halpern, C.B. 2007. The soil seed bank of a montane meadow: consequences of conifer encroachment and implications for restoration. Canadian Journal of Botany 85: 557-569.

League, K. \& Veblen, T. 2006. Climatic variability and episodic Pinus ponderosa establishment along the forest-grassland ecotones of Colorado. Forest Ecology and Management 228: 98-107.

Lingua, E., Cherubini, P., Motta, R. \& Nola, P. 2008. Spatial structure along an altitudinal gradient in the Italian central Alps suggests competition and facilitation among coniferous species. Journal of Vegetation Science 19: 425-436.
Loosmore, N.B. \& Ford, E.D. 2006. Statistical inference using the $\mathrm{G}$ or $\mathrm{K}$ point pattern spatial statistics. Ecology 87: 1925-1931.

Lotan, J.E. \& Critchfield, W.B. 1990. Pinus contorta Dougl. ex. Loud. Lodgepole pine. In: Burns, R.M. \& Honkala, B.H. (tech. coords.) Silvics of North America: 1. Conifers. pp. 604-629. Agriculture Handbook 654. USDA Forest Service, Washington, DC, US.

Magee, T.K. \& Antos, J.A. 1992. Tree invasion into a mountain-top meadow in the Oregon Coast Range, USA. Journal of Vegetation Science 3: 485-494.

Miller, E.A. \& Halpern, C.B. 1998. Effects of environment and grazing disturbance on tree establishment in meadows of the central Cascade Range, Oregon, USA. Journal of Vegetation Science 9: 265-282.

Minore, D. 1979. Comparative autecological characteristics of Northwestern tree species, a literature review. USDA Forest Service General Technical Report PNW-GTR 87, Portland, OR, US.

Miriti, M.N. 2006. Ontogenetic shift from facilitation to competition in a desert shrub. Journal of Ecology 94: 973-979.

Moeur, M. 1993. Characterizing spatial patterns of trees using stem-mapped data. Forest Science 39: 756-775.

Moore, M.M. \& Huffman, D.W. 2004. Tree encroachment on meadows of the North Rim, Grand Canyon National Park, Arizona, U.S.A. Arctic, Antarctic, and Alpine Research 36: 474-483.

Morrison, P.H. \& Swanson, F.J. 1990. Fire history and pattern in a Cascade Range landscape. USDA Forest Service General Technical Report PNW-GTR-254, Portland, OR, US.

Motta, R. \& Nola, P. 2001. Growth trends and dynamics in sub-alpine forest stands in the Varaita Valley (Piedmont, Italy) and their relationships with human activities and global change. Journal of Vegetation Science 12: 219-230.

Norman, S.P. \& Taylor, A.H. 2005. Pine forest expansion along a forest-meadow ecotone in northeastern California, USA. Forest Ecology and Management 215: 51-68.

Parish, R., Antos, J.A. \& Fortin, M.-J. 1999. Stand development in an old-growth subalpine forest in the southern interior of British Columbia. Canadian Journal of Forest Research 29: 1347-1356.

Pausas, J.G., Bonet, A., Maestre, F.T. \& Climent, A. 2006. The role of the perch effect on the nucleation process in Mediterranean semi-arid oldfields. Acta Oecologica 29: 346-352.

Peltzer, D.A. 2001. Plant responses to competition and soil origin across a prairie-forest boundary. Journal of Ecology 89: 176-185.

Perry, G.L.W., Miller, B.P. \& Enright, N.J. 2006. A comparison of methods for the statistical analysis of spatial point patterns in plant ecology. Plant Ecology 187: 59-82.

Peters, D.P.C., Jin, Y. \& Gosz, J.R. 2006. Woody plant invasion at a semi-arid transition zone: importance of 
ecosystem type to colonization and patch expansion. Journal of Vegetation Science 17: 389-396.

Picon-Cochard, C., Coll, L. \& Balandier, P. 2006. The role of below-ground competition during early stages of secondary succession: the case of 3-year-old Scots pine (Pinus sylvestris L.) seedlings in an abandoned grassland. Oecologia 148: 373-383.

Pugnaire, F.I., Armas, C. \& Valladares, F. 2004. Soil as a mediator in plant-plant interactions in a semi-arid community. Journal of Vegetation Science 15: 85-92.

Rakestraw, L. \& Rakestraw, M. 1991. History of the Willamette National Forest. USDA Willamette National Forest, Eugene, OR, US.

Reisman-Berman, O. 2007. Age-related change in canopy traits shift conspecific facilitation to interference in a semi-arid shrubland. Ecography 30: 459-470.

Ripley, B.D. 1977. Modelling spatial patterns. Journal of the Royal Statistical Society, London. Series B 39: 172-212.

Rochefort, R.M., Little, R.L., Woodward, A. \& Peterson, D.L. 1994. Changes in the distribution of subalpine conifers in western North America. A review of climate and other factors. The Holocene 4: 89-100.

Runkle, J.R. 1981. Gap regeneration in some old-growth forests of the eastern United States. Ecology 62: 10411051.

Sanchez Meador, A.J., Moore, M.M., Bakker, J.D. \& Parysow, P.F. 2009. 108 years of change in spatial pattern following selective harvest of a Pinus ponderosa stand in northern Arizona, USA. Journal of Vegetation Science 20: 79-90.

Scholes, R.J. \& Archer, S.R. 1997. Tree-grass interactions in savannas. Annual Review of Ecology and Systematics 28: 517-544.

Siemann, E. \& Rogers, W.E. 2003. Changes in light and nitrogen availability under pioneer trees may indirectly facilitate tree invasions of grasslands. Journal of Ecology 91: 923-931.

Stokes, M.A. \& Smiley, T.L. 1968. An introduction to tree ring dating. University of Chicago Press, Chicago, IL, US.

Takaoka, S. \& Swanson, F.J. 2008. Change in extent of meadow and shrub fields in the central western Cascade Range, Oregon. The Professional Geographer 60: $1-14$

Teensma, P.D.A. 1987. Fire history and fire regimes of the central western Cascades of Oregon. Ph.D. Dissertation. University of Oregon, Eugene, OR, US.

Vale, T.R. 1981. Tree invasion of montane meadows in Oregon. American Midland Naturalist 105: 61-69.

Van Auken, O.W. 2000. Shrub invasions of North American semiarid grasslands. Annual Review of Ecology and Systematics 31: 197-215.

van der Maarel, E. 1990. Ecotones and ecoclines are different. Journal of Vegetation Science 1: 135-138.
Vittoz, P., Rulence, B., Largey, T. \& Freléchoux, F. 2008. Effects of climate and land-use change on the establishment and growth of cembran pine (Pinus cembra L.) over the altitudinal treeline ecotone in the Central Swiss Alps. Arctic, Antarctic, and Alpine Research 40: 225-232.

Weltzin, J.F. \& McPherson, G.R. 1999. Facilitation of conspecific seedling recruitment and shifts in temperate savanna ecotones. Ecological Monographs 69: 513-534.

Weisberg, P.J. \& Swanson, F.J. 2003. Regional synchroneity in fire regimes of western Oregon and Washington, USA. Forest Ecology and Management 172: 17-28.

Wiegand, T. \& Moloney, K.A. 2004. Rings, circles, and null-models for point pattern analysis in ecology. Oikos 104: 209-229.

Yarranton, G.A. \& Morrison, R.G. 1974. Spatial dynamics of a primary succession: nucleation. Journal of Ecology 62: 417-428.

\section{Supporting Information}

Additional Supporting Information may be found in the online version of this article:

Photo S1. Tree islands among the larger mosaic of meadow and forest at Bunchgrass Ridge, Willamette National Forest, Oregon.

Photo S2a (left) + S2b (right). Aerial photos of the study area in 1959 (left) and 1997 (right) illustrating rapid loss of meadow habitat during the latter half of the $20^{\text {th }}$ century. "Old" forests in the 1959 photo originated in the 1800s. Several areas were clearcut adjacent to the study area in the 1970s-1980s (1997 photo).

Photo S3. Young Pinus contorta colonizing open meadow. Old ( $\geq 90 \mathrm{yr}$ ) forest dominated by Abies grandis is in the background.

Photo S4a (left)+S4b (right). Recent and past facilitation of Abies grandis by Pinus contorta. In the left panel, $A$. grandis has recruited beneath young $P$. contorta. In the right panel, $A$. grandis of varying ages surround $P$. contorta (now a snag) that had established in the mid-1800s.

Please note: Wiley-Blackwell are not responsible for the content or functionality of any supporting materials supplied by the authors. Any queries (other than missing material) should be directed to the corresponding author for the article.

Received 26 March 2009; Accepted 24 February 2010. Co-ordinating Editor: Dr. Janos Podani. 